\title{
EL PRINCIPIO PRO ACTIONE COMO CRITERIO DE INTERPRETACION PARA ACCEDER AL PROCESO JUDICIAL
}

\section{THE PRINCIPLE PRO ACTION AS A CRITERION OF INTERPRETATION TO ACCESS THE JUDICIAL PROCESS}

DOI: https://doi.org/10.5377//rd.v42i1.12934

Un principio interpretativo que permite hacer real el acceso a la justica en la primera instancia de un proceso.

"Aún cuando todas las otras reglas sean escrupulosamente respetadas, la obra del legislador nada vale si no responde a la justicia”. Francesco Carnelutti.

\section{RESUMEN:}

El propósito de este trabajo es poner a disposición del jurista una razón fundamental para hacer efectivo el acceso a la justicia. Es un hecho notorio que muchos procesos judiciales se ven detenidos o hasta precluidos por los rigorismos y formalidades no trascendentales impuestos por interpretaciones cerradas de la norma adjetiva. En las siguientes líneas se pretende construir una idea procesal sobre la importancia de hacer uso de la tutela judicial efectiva, enfáticamente del principio pro actione y que la operatividad de esta fuente interpretativa del derecho, sea una herramienta para lograr el acceso a la justicia en las personas que litigan en los órganos jurisdiccionales.

PALABRAS CLAVES: Principio pro actione, acceso a la justicia, tutela judicial efectiva, derecho procesal.

\section{ABSTRACT:}

The purpose of this work is to make available to the jurist a fundamental reason to make effective access to justice. It is a notorious fact that many judicial processes are stopped or even precluded by the rigor and non-transcendental formality imposed by closed interpretations of the adjective rule. In the following lines it is intended to build a procedural idea about the importance of making use of effective judicial protection, emphatically of the pro actione principle and that the operation of this interpretive source of law, is a tool to achieve access to justice in the people who litigate in the courts.

KEY WORDS: Pro actione principle, access to justice, effective judicial protection, procedural law.

Fecha de recepción: $31 / 8 / 2021$

Fecha de aprobación: 23/9/2021

1 Abogado candidato a Máster en Derecho Procesal Civil, Maestrante en Derecho Penal y Procesal Penal, Letrado de Sala Constitucional en la Corte Suprema de Justicia de Honduras. Correo Electronico: edwinalvarenga96@gmail.com 


\section{INTRODUCCIÓN}

Después de una década de haber entrado en vigencia el Código Procesal Civil en Honduras², es necesario poder estudiar la operatividad de ciertos principios que vinieron agregados a su nacimiento. El artículo 1 de la norma supra mencionada, es bastante amplio al mencionar el derecho de acceso a la juzgados y tribunales, desarrollando en su contenido el principio a la tutela judicial efectiva y la obligación de los órganos jurisdiccionales de remover los impedimentos que se puedan producir para que este se realice, así mismo posibilitar el ejercicio del acceso a la justicia.

En el mundo del derecho no podemos desconocer la existencia de las tradiciones jurídicas. El derecho procesal en la región es producto de una profunda reforma donde se transito de lo procedimental a lo procesal. En cuanto al paradigma procedimental es patente que estaba ceñido de una cultura legalista, rigorista y parsimoniosa, lo que permitía en algunos casos arbitrariedades o incongruencias. En cuanto al paradigma procesal podemos decir que trajo consigo, agilidad, efectividad y garantías, elementos que permiten mayor balance entre juzgador y justiciables. Lo interesante de todo esto es que con la entrada en vigor de la reforma procesal los vestigios de la tradición procedimental siguen operando en la sustanciación jurisdiccional.

En algunas escuelas de derecho se sigue explicando articulo por articulo la ley adjetiva y de esa forma se continúa promoviendo la aplicación de la ley "a raja tabla". Es decir, se sigue resaltando la aplicación rigorista de la norma, olvidándonos que la reforma no solo trajo consigo un cambio 2 DECRETO No. 211-2006, con vigencia a partir del 1 de noviembre del 2010. de artículos y procesos, sino también un cambio en las formas y una potencialización en la aplicación del derecho. El estudio de la norma procesal va más allá de su contenido normativo, este debe hacerse poniendo en practica una serie de principios que permita in fine, una verdadera realización del Derecho sustantivo.

Elprincipioproactioneesunodeesos principios que conducen a una adecuada ampliación de la norma procesal. Su operatividad permite una interpretación mas profunda de la norma además de la puesta en marcha de la tutela judicial efectiva. Es importante resaltar que los principios generales del derecho y la jurisprudencia, son una fuente importante dentro del derecho interno. La página web Wikipedia www.wikipedia.org -los define como: "Los principios generales del derecho y la jurisprudencia, [...] complementan y sirven para interpretar las normas que han de ser aplicadas, por lo que son fuentes que en la práctica tienen mucha importancia". - En el caso del principio pro actione, es admitido por razón de materia, y su utilidad es interpretativa. En consecuencia, no detenta la posición de principio general, pero si de principio por razón de materia.

El desarrollo del potencial y usanza de los principios tiene como finalidad en este trabajo, cambiar el paradigma de aplicar el derecho bajo el auspicio de una fuente unitaria, y así lograr proveer al jurista nuevos teorías y sobre todo una nueva visión sobre la aplicación del derecho procesal. Existe quienes se consultarán si el principio pro actione solo opera en el derecho procesal civil, la respuesta es: no. Recordemos que cuando hablamos de la reforma procesal no solo se dio en la materia civil, también se dio en la materia penal, y hoy en día, en la región también contamos con sistemas procesales en materia contencioso administrativo y laboral. 


\section{METODOLOGIA}

La metodología es una forma clara y precisa de cómo se alcanzar uno de los objetivos específicos propuestos en una investigación jurídica. Para el tratadista Cesar Stuardo Rivera la metodología (métodos de investigación) hace referencia al proceso lógico mediante el cual se someterá a prueba o demostración la hipótesis planteada, o se hará, en su caso, la construcción de la misma. En el presente articulo se ha hecho usanza del método teórico (aplicado al derecho) AnálisisSíntesis: un formato que adquiere utilidad cuando el objetivo de la investigación es estudiar la relación del objeto, o sus partes, con otros elementos del sistema al que pertenece.

Para lograra una coherencia en este trabajo, hemos analizado los presupuestos procesales desde un punto de vista general y así mismo la aplicación de un principio interpretativo que permite una interpretación favorable al acceso al proceso, por ende, a la justicia. En cuestión nuestra óptica se ha enfocado en el análisis del la tutela judicial efectiva y su consecuencia a través del principio pro actione dentro de la norma, así proveyendo una síntesis de como la aplicación de este criterio, es una herramienta para lograr dar trámite sin dilación a una petición ante el órgano jurisdiccional.

\section{LA TUTELA JUDICIAL EFECTIVA}

En aras de poder conocer el a cabalidad la operatividad del principio pro actione, es necesario comprender su desprendimiento. Para tal tarea nos acercaremos a la Tutela Judicial Efectiva (De aquí en adelante La Tutela) que es donde se desprende el mencionado precepto.
La Tutela es el derecho que tiene toda persona a ejercitar la defensa de sus intereses legítimos ante la Justicia, con la correspondiente intervención de los órganos judiciales. Toda vez que una persona considera que se han vulnerado sus derechos, puede recurrir a los tribunales para que analicen la situación y, si es pertinente, le restituyan en sus derechos o reparen los daños sufridos de la manera en que indique la ley.

La Tutela está configurada como derecho en los textos constitucionales y convencionales, en la Constitución de España en el artículo 24, en la Constitución de Honduras se infiere del artículo 82 , y en materia de derecho internacional, en el artículo 25 de la Convención Americana de Derechos Humanos. En la carta magna esta contextualizado como derecho genérico a la justicia y en los tratados como derecho humano al proceso debido internacionalmente positivizado, en ambos esta plasmado como un derecho de índole fundamental.

Este derecho incrustado en normas de primer orden también se pone en marcha como principio, al momento de desarrollar un proceso jurisdiccional. El procesalista Diego Diez (2014) estipula a La Tutela como derecho al proceso, con un contenido poliédrico, multiforme, integrado por derechos e instrumentos varios. Un derecho que comprende: acceder a la justicia, obtener una resolución motivada sobre el fondo, acceder a los recursos establecidos en la ley, y el acceder a la ejecución de lo juzgado. (pp. 228) En sintonía con esta descripción la Corte Suprema de Justicia la desarrolla como un principio ${ }^{3}$ el cual está compuesto por 1. Derecho de Acceso a la Justicia; 2. Derecho a una resolución fundada en derecho; 3. Derecho de acceso a los recursos, no solo por previsión legal de los mismos, sino de obtener una 3 Ver Casación Penal 255-2015, Corte Suprema de Justicia, Honduras.

Revista de Derecho. Vol. 42, No. 1, Año 2021 113 
respuesta ante su interposición; 4. Derecho a la Tutela Cautelar; y 5. Derecho a la ejecución. En este prius lógico podemos concluir que La Tutela tiene como función procesal garantizar un debido proceso a quienes acuden al Juzgado o Tribunal. $\mathrm{Su}$ cometido es proveer ciertos derechos que se vuelven de aplicación ineludible por su carácter garantista. En la misma línea su aplicación pretende asegurar una correcta configuración del derecho procesal con igualdad de oportunidades para las partes involucradas, con decisiones a favor o en contra, que satisfagan las pretensiones de seguridad jurídica que tiene la sociedad.

En el interior de esa gama de derechos que gravitan sobre La Tutela, cada uno transita sobre una acción que da paso a una consecuencia jurídica. Los implicados (como parte o encargados) en el procedimiento, se ven llamados a poner en práctica cada derecho que garantice la tutela judicial efectiva y así poder brindar dentro de un marco jurídico, justicia real. Ese transito que hemos mencionado esta ceñido de ciertos principios interpretativos, los cuales son un parámetro en el accionar procesal, por otro lado, también permiten un desenvolvimiento idóneo del derecho de acceso al proceso.

\section{EL PRINCIPIO PRO ACTIONE Y SU OPERATIVIDAD}

Cuando nos enfrentamos a un proceso judicial debemos hacerlo por los cauces establecidos en la ley. Los instrumentos jurídico procesales, establecen una serie de pasos a seguir para poder hacer valer nuestra pretensión o nuestro rechazo. Las normas adjetivas están contenidas en los Códigos o Leyes Procesales. Estos cuerpos normativos contienen una serie de acciones que se deben ejercitar para la concesión de un objetivo jurídico. Por ejemplo, cuando se desea la declaración de un derecho sobre un bien inmueble, el cual no está en posesión de quien dice ser su dueño legítimo, el Código establece el proceso por el cual se debe ventilar la declaración de tal pretensión, estipula bajo qué tipo de demanda, la forma de ofertar y sustanciar medios de prueba para constatar los hechos, y la manera en que el juzgado dará respuesta a la pretensión. Así también los derechos y formas de rechazo, de quien es demandado. Es decir, estipulara todo un camino a transitar para lograr una satisfacción jurídica.

Cada una de las acciones o ejercicios, de los cuales hagan uso las partes están sujetos a presupuestos. Los presupuestos procesales son los requisitos o condiciones que deben cumplirse para la iniciación o desarrollo válido de un proceso. (Lopez Olvera, 2013) en tanto podemos decir que son disposiciones imperativas para que las actuaciones del proceso puedan llevarse a cabo y de esa manera obtener una respuesta favorable o desfavorable a la petición que motivo dicho suceso. Estas condiciones además de ser acatadas por las partes desde el momento de la presentación de la demanda o petición de medida cautelar, deben ser observadas por los jueces ante quienes se presenten. A este punto cabe resaltar que los presupuestos procesales son de orden público y su configuración debe estar previamente establecida en la ley.

Comprendida la relevancia de los presupuestos, podemos afirmar que el principio pro actione opera en conexión con los presupuestos, y como consecuencia de ello, en los actos del proceso. Su efectividad radica en servir como principio interpretativo, a través del él se exige a los órganos jurisdiccionales la exclusión de determinadas aplicaciones o interpretaciones de los presupuestos procesales, que eliminen u 
obstaculicen injustificadamente el derecho del litigante a que un órgano jurisdiccional conozca y resuelva sobre la pretensión a él sometida ${ }^{4}$.

Este principio exige que los órganos judiciales, al interpretar los requisitos procesales legalmente previstos, tengan presente la ratio de la norma con el fin de evitar que los meros formalismos o entendimientos no razonables de las normas procesales impidan un enjuiciamiento de fondo del asunto, vulnerando las exigencias del principio de proporcionalidad. ${ }^{5}$

Es decir, este principio cumple una función de flexibilizar las interpretaciones que puedan hacerse sobre los requisitos exigidos por la ley para que las partes puedan ingresar al proceso. Cuando hablamos de flexibilizar no referimos a la adaptación de las formas y la susceptibilidad de cambios o variaciones según las circunstancias o necesidades. Cuando entramos a un proceso muchas veces podemos encontrarnos con laberintos y pasajes necesarios pero franqueables, es ese en el momento que el principio pro actione opera como agente encargado de hacer efectivo el derecho a la tutela judicial.

En el mismo orden de ideas, este principio opera, cuando que el juzgador interpreta los requisitos y presupuestos procesales de la manera más favorable al ciudadano, con el fin de evitar que el acceso a la justicia sea degradado o imposible de ejercer para el justiciable. Para los cual el juez o la jueza debe seleccionar dentro de las normas legales que establecen requisitos de admisibilidad al proceso la interpretación más favorable a la efectividad de La Tutela.

4 Definición del Principio Pro Actione desglosada en el diccionario panhispánico del español jurídico, 2020

5 https://www.expansion.com/diccionario-juridico/principiopro-actione.html
Este criterio no significa que los juzgadores o juzgadoras deban convertirse en deformadores de los requisitos del proceso. La Sala Primera del Tribunal Constitucional ha dicho:

El derecho a la jurisdicción no consiente interpretaciones y aplicaciones de los requisitos legales caracterizadas por el rigorismo, el formalismo o la desproporción entre los fines que preservan y la consecuencia del cierre del proceso que conllevan, con eliminación $u$ obstaculización injustificada del derecho a que un órgano judicial resuelva sobre el fondo de la pretensión a él sometida.

No obstante, ese criterio antiformalista no puede conducir a prescindir de los requisitos que se establecen en las leyes y que ordenan el proceso en garantía de los derechos de todas las partes. El principio pro actione no debe entenderse tampoco como la forzosa selección de la interpretación más favorable a la resolución del problema de fondo de entre todas las posibles de las normas aplicables. ${ }^{6}$

De la jurisprudencia de esta alta corte podemos resaltar un punto muy importante, el principio pro actione no debe ser una vía para deformar el proceso, solo debe servir como para proveer un real acceso a la justicia a través de un efectivo derecho a la jurisdicción.

Con esto también podemos establecer que bajo la idea de <buscar la interpretación mas favorable>, no nos referimos en si a favorecer a las partes en la admisibilidad de sus demandas o peticiones, si no ha interpretar la disposición procesal en el sentido mas favorable a la efectividad de La Tutela, en el sentido de evitar 6 Véase Sentencia 231/2012.Tribunal Constitucional Español

Revista de Derecho. Vol. 12, No. 1, Año 2021 -115 
formalismos enervantes contrarios al espíritu de la ley procesal. Por tanto, podemos decir que si el juez o jueza se enfrenta a dos interpretaciones, no está obligado a elegir la mas favorable a la admisión de la demanda o petición ya que la exigencia primaria es que la decisión que tome sea razonada y con fundamento.

Con lo que hasta aquí hemos examinados podemos colegir dos puntos nucleares sobre el efecto del principio en cuestión, el acceso a la jurisdicción y el derecho a la acción, en relación a este último ha dicho La Corte Suprema de Justicia en su sentencia CC-283-14:

Principio Pro Actione, [es] el que postula a favor de la mayor garantía y de la interpretación más favorable al ejercicio del derecho de acción $\mathrm{y}$, por lo tanto, en el sentido de asegurar, en lo posible, más allá de las dificultades de índole formal, una decisión judicial sobre el fondo de la cuestión objeto del procedimiento.

También con estas líneas jurisprudenciales es perceptible que el principio pro actione tiene un alcance operativo en diferentes materias procesales como por ejemplo el derecho procesal penal, desde luego en todas las que sean sujeto a la tutela judicial efectiva. Claro, el tratamiento dependerá de la casuística de cada rama procesal.

\section{CONCLUSION}

- Podemos decir que el principio pro actione busca evitar que los rigorismos excesivos, interpretaciones arbitrarias, irrazonables o desproporcionadas sean parte del acceso o no al proceso judicial. Operando como criterio de interpretación y buscando que se pondere la inadmisión rigorista $\mathrm{y}$ formalmente excesiva y los fines de la causa y los intereses que pueden verse sacrificados. Dicho principio puede ser aplicado como criterio de interpretación o ser invocado para la obtención de una respuesta razonada por parte del juzgador. El cometido de su existencia es no permitir que los óbices procesales afecten el ingreso al proceso, proveyendo una interpretación lógica o la oportunidad de subsanación al involucrado.

\section{BIBLIOGRAFIA}

- Alfredo de Diego Diez, El derecho a la tutela judicial efectiva, OIM, Tegucigalpa, 2014

- Alfredo de Diego Diez, La apelación en el Código Procesal Civil Hondureño, OIM, Tegucigalpa, 2014

- César S. Rivera Licona, Manual de Iniciación a la Investigación Jurídica, Ciudad Universitaria Tegucigalpa M.D.C. 2020

- Corte Suprema de Justicia Honduras, 2016, Magistrada Rina Auxiliadora Alvarado Moreno, Casación Civil 283-14.

- Corte Suprema de Justicia Honduras, 2019, No se indica el ponente, Casación Penal 255-15.

- Diccionario panhispánico del español jurídico, 2020.

- Enrique García Pons, aporia del principio pro actione en el ámbito temporal del proceso debido: Crítica de la STC 136/1997, Revista española de derecho constitucional Vol. 17 Núm. 51 Pág. 317-346.

- Juan Luis Gómez Colomer y otros, 2019 Derecho Jurisdiccional I Parte General 27a edición, España, Tirant lo Blanch.

- Miguel Alejandro López Olvera, 2013, Los presupuestos procesales y la tutela judicial efectiva, Justicia contenciosa administrativa, México, Congreso internacional, Universidad Nacional Autónoma de México. 